\title{
O CONTEXTO GEOMORFOLÓGICO E A DINÂMICA MORFOMÉTRICA DA BACIA HIDROGRÁFICA DO RIO TENENTE AMARAL/MT
}

\author{
Ivaniza de Lourdes Lazzarotto Cabral ${ }^{1}$ \\ Cleberson Ribeiro de Jesuz ${ }^{2}$
}

\begin{abstract}
Resumo
O trabalho realizou uma análise geomorfológica da bacia hidrográfica do rio Tenente Amaral a partir da elaboração do mapa geomorfológico na escala de 1:80.000, onde foi possível identificar as particularidades em termos das formas do relevo e os seus respectivos processos. As atividades envolvidas na pesquisa foram: levantamento bibliográfico; elaboração de base cartográfica e de mapas morfométricos, interpretação imagens de satélite, elaboração e análise do mapa do geomorfológico. No contexto regional, esta área faz parte das unidades morfoesculturais da Depressão Interplanáltica de Rondonópolis e do Planalto e Chapada dos Guimarães. Na primeira unidade morfoescultural foram identificados padrões de relevo derivados dos processos vinculados ao recuo da superfície planáltica com destaque para feições geomorfológicas de escarpas erosivas, rampas coluvionares, superfícies erodidas/rebaixadas, relevo residual e vales encaixados, e na segunda têm-se eventos de erosão superficial (em meio agropecuário/vegetação nativa primária e/ou secundária), vales encaixados, sistemas de voçorocamentos em cabeceiras de drenagem e superfícies com feições trapeizoidais.
\end{abstract}

Palavras chave: Mapeamento Geomorfológico; Feições geomorfológicas; Bacia hidrográfica.

\section{GEOMORPHOLOGICAL DYNAMICS OF THE TENENTE AMARAL/MT RIVER BASIN}

\begin{abstract}
The work carried out geomorphological analysis of the hydrographic basin of Tenente Amaral river from the elaboration of a geomorphological map in the scale of 1:80.000, where it was possible to identify the particularities in terms of the relief forms and their respective processes. The activities involved in the research were: bibliographic survey, elaboration of cartographic base and morphometric maps, interpretation of satellite images, elaboration and analysis of the geomorphological map. In the regional context, this area is part of the morphosculptural units of the interplanaltic depression of Rondonopolis and the plateau of Chapada dos Guimarães. In the first morpho-sculptural unit, relief patterns derived from processes linked to the retreat of the plateau surface were identified, with emphasis on

\footnotetext{
${ }^{1}$ Professora na Universidade Federal de Mato Grosso. Doutora em Geografia Física pela Universidade de São Paulo. Email: ivanizacabral@ hotmail.com.

${ }^{2}$ Professor do Departamento de Geografia da Universidade Federal de Mato Grosso. Doutor em Geografia pela Universidade Federal de Goiás. Email: clebersonjesuz@ufmt.br
} 
geomorphological features of erosive cliffs, colluvial ramps, eroded/lowered surfaces, residual relief and embedded valleys; and in the second one, there are erosion events (in agricultural and cattle raising environment/primary and/or secondary native vegetation), embedded valleys, gully systems in drainage headwaters and surfaces with trapezoidal features.

Key-words: Geomorphological mapping; Geomorphological features; Hydrographic basin.

\section{DINAMICIDAD GEOMORFOLÓGICA DE LA CUENCA DEL RÍO AMARAL TENENTE /MT}

\section{Resumen}

El trabajo llevó a cabo un análisis geomorfológico de la cuenca hidrográfica del río Tenente Amaral a partir de la elaboración de un mapa geomorfológico en la escala de 1: 80,000, donde fue posible identificar las particularidades en términos de las formas de relieve y sus respectivos procesos. Las actividades involucradas en la investigación fueron: levantamiento bibliográfico, elaboración de bases cartográficas y mapas morfométricos, interpretación de imágenes satelitales, elaboración y análisis del mapa geomorfológico. En el contexto regional, esta área es parte de las unidades morfo-escultóricas de la depresión interplanaltica de Rondonopolis y la meseta de Chapada dos Guimarães. En la primera unidad morfoescultórica, se identificaron patrones de relieve derivados de procesos vinculados a la retirada de la superficie de la meseta, con énfasis en las características geomorfológicas de acantilados erosivos, rampas coluviales, superficies erosionadas / bajadas, relieve residual y valles incrustados; y en el segundo, hay eventos de erosión (en ambientes agrícolas y ganaderos / vegetación nativa primaria y / o secundaria), valles incrustados, sistemas de quebradas en cabeceras de drenaje y superficies con características trapezoidales.

Palabras clave: Mapeo geomorfológico; Características geomorfológicas; Cuenca hidrográfica.

\section{INTRODUÇÃO}

A Geomorfologia tem por objetivo analisar as formas do relevo, buscando compreender os processos pretéritos e atuais, representando um campo de conhecimento específico e sistematizado. Como parte da temática geográfica, constitui importante subsídio para a apropriação racional do relevo, como recurso ou suporte, pois considera a conversão das propriedades geoecológicas em sócio-reprodutoras. Portanto, incorpora a compreensão das forças antagônicas, endógenas e exógenos (CHOLLEY, 1950; PENCK, 1953; CASSETI, 1991).

Dessa forma, vários autores concordam que as formas do relevo são ao mesmo tempo consequências da atuação de energias definidas como forças endógenas (dobras, falhas, 
vulcões, terremotos) e forças exógenas (desgaste e acumulação). Em virtude das variações topográficas e morfológicas abre-se espaço para a interferência da ação da gravidade que possibilita o deslocamento de matéria e energia líquida ou sólida das partes mais altas para as mais baixas, em um processo contínuo de desgaste dos terrenos elevados e de acumulação nos segmentos mais baixos das superfícies emersas dos continentes.

O estudo do relevo a partir da compartimentação geomorfológica possibilitou analisar os aspectos que individualizam a área em questão, viabilizando o entendimento das formas de evolução do relevo e a compreensão dos processos morfodinâmicos atuantes (BORGES, 2008).

O conhecimento das superfícies tem uma importância direta no processo de ocupação, compreendendo observações relativas aos diferentes níveis topográficos, características do relevo, e a análise geomorfológica é um importante instrumento de apoio para determinar ações preventivas referente aos impactos ambientais (CASTRO e SALOMÃO, 2000).

No contexto deste trabalho a ciência geomorfológica surge como fonte de conhecimento da esfera ambiental, cujo objetivo fundamenta-se na elucidação da evolução das formas do relevo, em um dos diversos ambientes do estado de Mato Grosso, com vista às progressivas alterações nos distintos ambientes que constituem os sistemas da região CentroOeste do Brasil, impulsionado pelo rápido avanço da fronteira agrícola brasileira nas últimas décadas do século XX.

Assim, na etapa inicial de implantação das práticas vinculadas a produção agrícola empresarial a intervenção nas unidades de paisagem da região acontece sobre os elementos sistêmicos da cobertura vegetal, junto com o biológico, hídrico e antrópico. Estes são substituídos e/ou alterados pela pastagem ou pela monocultura e, em muitos casos pelas duas modalidades conjuntas. Paralelamente a este fluxo interventor, numa escala mais específica da questão, estão os fatos relacionados à dinâmica de superfície, responsáveis pela geração do recurso apropriado pela referida atividade, ou seja, intervenção na dinâmica dos sistemas morfopedológicos.

A produção agrícola em escala empresarial no Estado ocorre quase exclusivamente nas superfícies dos Planaltos (Parecis e Guimarães) devido às próprias condições topográficas dos mesmos. Ao se tratar de um ambiente morfopedológico "apropriado" para o desenvolvimento da agricultura mecanizada, as superfícies do Planalto dos Guimarães foram convertidas para grandes propriedades agrícolas dedicadas principalmente à cultura da soja, milho, algodão com o objetivo de gerar divisas para a economia brasileira. 
Neste contexto, sob as diferentes perspectivas vários trabalhos abordam o assunto sobre os mais diversos problemas decorrentes da introdução da agricultura empresarial no estado de Mato Grosso, em especial para o recorte do Planalto dos Guimarães, onde se observa que as discussões pertinentes a compreensão das realidades do relevo em determinados trechos também foram amplamente apresentadas (VASCONCELOS, 1998; SEPLAN, 2007; ROSS, 2014; JESUZ e CABRAL, 2016).

Sendo assim, o trabalho teve por meta fazer a análise geomorfológica da bacia hidrográfica do rio Tenente Amaral a partir da elaboração do mapa geomorfológico na escala de 1:80.000. O estudo também contou com o conhecimento integrado de informações sobre o sistema de drenagem, geologia, tipos de solos, vegetação, uso da terra e as formas do relevo do contexto regional da área onde está situado o referido sistema de drenagem.

A análise evidencia questões sobre a demanda das atividades agropecuárias nas superfícies planálticas no Estado indicando seus impactos, principalmente, em nível de bacias hidrográficas, forma pouco abordada para efetivar pesquisas na região. Além disso, os estudos geomorfológicos atrelados às condicionantes biofísicas ainda apresentam muitas lacunas na pesquisa em escala local/regional em Mato Grosso. Deste modo, o trabalho visa contribuir para o conhecimento sobre a dinâmica entre as forças atuantes no sistema da bacia hidrográfica do rio Tenente Amaral e, no contexto mais amplo, para bacia hidrográfica do rio São Lourenço, o qual apresenta demanda em termos de conhecimento para atender o seu comitê de bacia hidrográfica.

\section{A BACIA HIDROGRÁFICA DO RIO TENETE AMARAL E O SEU CONTEXTO}

A bacia hidrográfica do rio Tenente Amaral faz parte do sistema São Lourenço, um dos principias tributários do rio Cuiabá. É uma área do alto curso do setor nordeste da bacia hidrográfica do rio Paraguai, perfazendo uma das parcelas do sistema do entorno da parte norte da Planície do Pantanal. A área da bacia hidrográfica do rio Tenente Amaral localiza-se a $120 \mathrm{Km}$ a leste da cidade de Cuiabá, situada entre as coordenadas de $15^{\circ} 08^{`}$ a $16^{\circ} 00^{`} \mathrm{~S}$ e $55^{\circ} 05^{`}$ a $55^{\circ} 35^{`} \mathrm{~W}$, correspondendo a uma extensão territorial de $859 \mathrm{Km}^{2}$ (Fig. 1). 
Figura 1 - Mapa de localização da bacia hidrográfica do rio Tenente Amaral - MT.

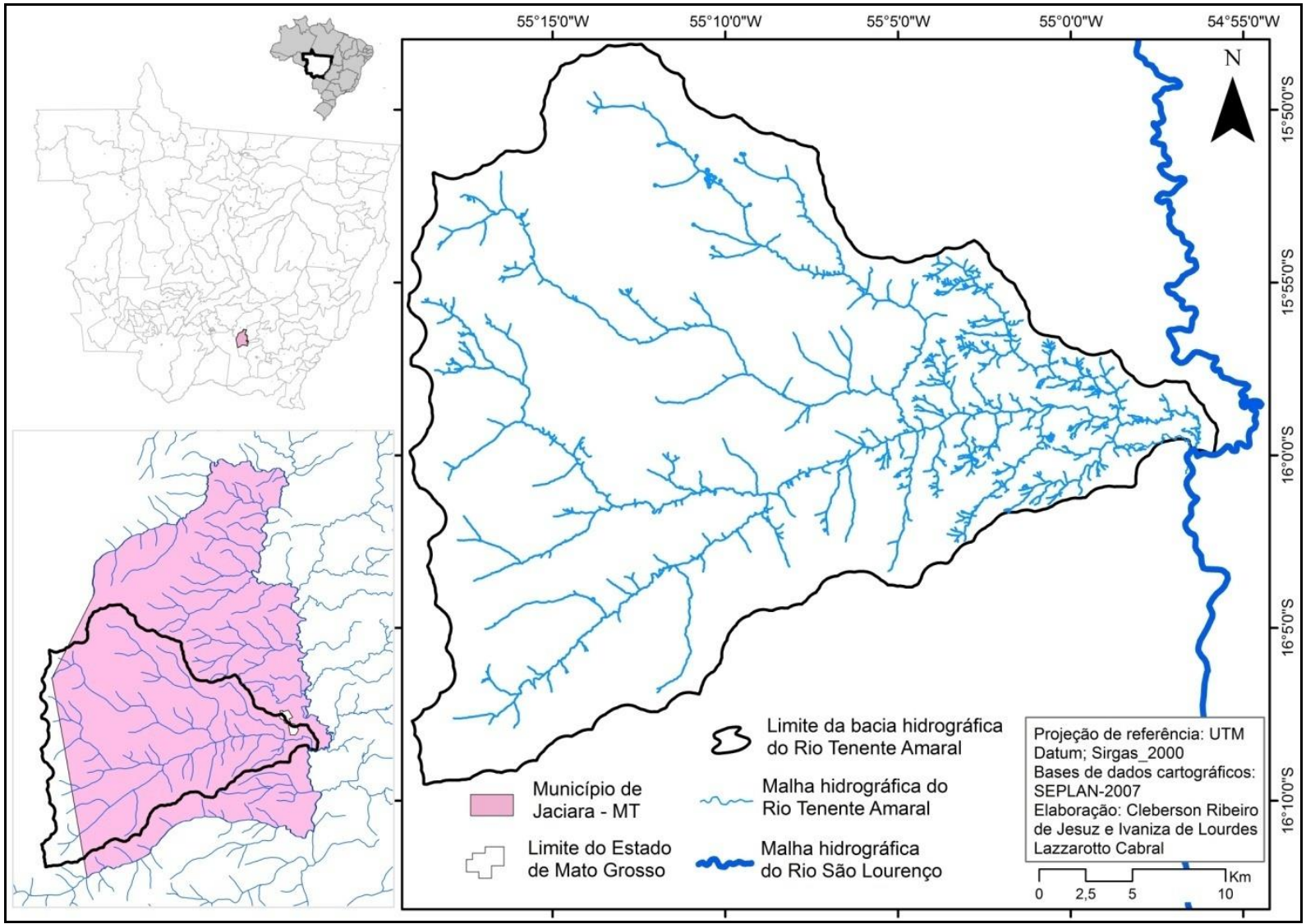

Fonte: Dados cartográficos da Secretaria de Estado de Planejamento e Gestão/MT - SEPLAN (2007).

Ross (2013) evidencia que na análise geomorfológica a interpretação morfogenética do relevo envolve a compreensão da relação entre os processos tectônicos e erosivos e, a atual conformação do relevo brasileiro implica no entendimento da relação espacial entre estrutura e tectônica pós-cretácea de um lado e atividades erosivas de outro, sendo esta última mais significativa ao longo do Quaternário devido às variações climáticas. Seguindo essa proposição é importante mostrar que o sistema São Lourenço tem grande parte dos seus tributários localizados nas superfícies do Planalto e Chapada dos Guimarães, e Depressão Interplanáltica de Rondonópolis. No contexto regional evolutivo do conjunto de formas do relevo estas unidades passaram por vários eventos do conjunto de fatos geológicos próprios da dinâmica das bacias de sedimentação em ambiente geológico de "estabilidade" onde, ao longo da sua história geológica, especialmente a que abrange o pós-terciário, os eventos da morfodinâmica promoveram o reafeiçoamento cíclico do modelado, expressado pelas três unidades de relevo destacadas inicialmente.

Corroborando com os fatos mencionados destaca-se os trabalhos de Ab'Saber (1972), pois, infere o contexto das superfícies de erosão no entendimento do relevo brasileiro, 
principalmente os derivados de bacia de sedimentação. Estes autores apresentam os níveis morfológicos de erosão referente às Superfícies Intermontanas e os níveis de erosão das Superfícies Interplanálticas ou embutidas que correspondem as depressões esculpidas em borda de bacias sedimentares ao longo do Plioceno-Pleistoceno, ou seja, depressões circundantes as grandes bacias sedimentares.

Em relação à característica genética das superfícies de erosão, Ab’Saber (1972) redefiniu a classificação anterior com base nos processos circundenudacionais nas estruturas das bacias de sedimentação e dos maciços antigos, propondo a seguinte divisão: (I) Depressões Periféricas Subseqüentes; (II) Depressões Monoclinais; (III) Depressões Marginais com forte Eversão e, (IV) Depressões Marginais com Eversão e Formação de Bacias Detríticas.

Sobre as evidências das formas do relevo, Casseti (2005) destaca que a esculturação das superfícies Interplanálticas é marcada por formas erosivas e residuais, tendo como início a dissecação da superfície através da ação erosiva da rede de drenagem que evolui por erosão remontante, e a transição entre a borda da bacia em relação a superfície Interplanáltica pode ocorrer de forma gradativa com decaimento topográfico escalonado, e/ ou de forma abrupta delimitada por Front de Cuesta Desdobrada onde marca o limite entre o Reverso de Cuesta superfície de aplanamento, e a depressão - superfície rebaixada.

As superfícies da bacia hidrográfica do rio Tenente Amaral fazem parte da unidade geomorfológica do Planalto dos Guimarães, onde prevalece o conjunto de formas Convexas e os Patamares Estruturais, sob diferentes ordens de grandeza e dissecação por parte da drenagem. Nestas superfícies a ação vertical desempenhada pelo sistema de drenagem constitui um dos principais processos situados ao longo dos eixos da drenagem principal (ROSS, 1995).

Outra abordagem em relação às condições do relevo na área da bacia é a proposta apresentada por Latrubesse et al., (1998). Nesta proposta sobre o relevo do estado de Mato grosso as superfícies da bacia hidrográfica do rio Tenente Amaral são explicadas a partir das proposições estabelecidas para o Sistema Denudacional com formas de relevo em contínuo processo geral de esculturação.

O contexto morfoestrutural da área onde está localizada a bacia hidrográfica do rio Tenente Amaral perpassa pelas estruturas dos sedimentos Paleomesozóico da Bacia Sedimentar do Paraná, representada pelas Superfícies Paleogênica Peneplanizada com Latolização (Terceário), arenitos ortoquartzíticos de granulometria grosseira da Formação 
Furnas (Devoniano) e arenitos finos com registros esporádicos de arenitos grosseiros e conglomeráticos em sua base (CAMARGO, 2011).

$\mathrm{Na}$ área da bacia hidrográfica em questão as condições da atmosfera revelam o ambiente típico da macrounidade climática de Clima Tropical Continental Alternadamente Úmido e Seco das Chapadas, Planaltos e Depressões de Mato Grosso. Em escala de maior detalhe, a área estudada apresenta as condições climáticas que expressam os ambientes denominados Mesotérmico dos Topos de Cimeira dos Chapadões e Mesotérmico Úmido dos Baixos Planaltos e Depressões (TARIFA, 2011).

Referente aos componentes fitogeográficos, esta é uma das superfícies onde se destacam os compostos vegetais do Cerrado brasileiro (BRASIL, 1982; VASCONCELOS, 1998). Esta composição apresenta diversidade associada às condições dos solos que, em termos gerais, estão representados pelos Neossolos Quartzarênicos, Latossolos Vermelho, Latossolos Vermelho Amarelo, Argissolos e os solos Hidromórficos nos fundos dos vales.

Essas condições, junto com os fatores intrínsecos à produção geográfica do espaço brasileiro e do próprio Estado, promoveram inúmeras mudanças nas condições "originais" na região e, por sua vez na área deste sistema de drenagem. Dentre as várias intervenções as que mais se destacam são aquelas relacionadas à prática da agricultura mecanizada para desempenhar o cultivo da soja, milho, algodão, cana de açúcar, pecuária de corte e leiteira e a implantação de Pequenas Centrais Hidrelétricas - PCHs nos cursos d água que, na maioria das vezes apresentam condição de baixa capacidade hídrica.

Os levantamentos da World Wide Fund for Nature (WWF) Brasil em parceria com SOS Amazônia e a Empresa Brasileira de Pesquisa Agropecuária, efetivados na Bacia Hidrográfica do Alto Paraguai, reforçam a questão apresentada sobre uso da terra na área da Bacia Hidrográfica do rio Tenente Amaral (WWF BRASIL, 2011).

\section{MATERIAIS E MÉTODO}

No contexto teórico/metodológico, a condução da pesquisa teve suporte nas proposições apresentadas nos trabalhos de Bertrand (1971), Sotchava (1977) Tricart (1977), Monteiro (2000) e, especialmente, Penck (1953), Gerasimov e Mercesjacov (1968).

Nesta perspectiva, o interesse sobre as questões relacionadas à paisagem, foi uma das proposições consideradas na análise e representação das formas do relevo do sistema hidrográfico do rio Tenente Amaral, pois o seu conceber científico perpassa pela concepção estabelecida na comunicação existente sobre "paisagem" e "unidades de paisagem". 
Em termos práticos a análise, definição e a representação das formas do relevo tratadas foram estabelecidas a partir da proposta de Ross (1991, 1992, 2007). O mapeamento geomorfológico sob o viés dos estudos desenvolvidos por Ross se fundamenta na definição de uma legenda integrada, contendo informações das formas do relevo a partir das concepções vinculadas aos conceitos de morfoestrutura/morfoescultura de Gerasimov e Mercejacov (1968).

Essa concepção metodológica foi evidenciada por Ross (1992), o qual propõe uma classificação taxonômica do relevo para representar os aspectos fisionômicos das diferentes formas e tamanhos, baseado na gênese e na idade dessas formas, tendo em vista o significado morfogenético e as influências estruturais e esculturais no modelado conceituados como táxons, sendo estes divididos em seis unidades, abrangendo desde as unidades morfoestruturais, passando pelas unidades morfoesculturais, padrões de formas semelhantes, tipos de formas do relevo, tipos de vertente e numa escala de maior detalhe, contempla as formas de processos atuais, especialmente as erosões lineares e mecânicas.

Assim, para o desenvolvimento da pesquisa foram gerados dados primários e secundários, envolvendo atividades de gabinete, laboratório e trabalho de campo. Os dados primários foram obtidos em visitas in situ, por meio de atividades de campo, com coletas de materiais pedológicos, geomorfológicos e geológicos, registros fotográficos, descrição detalhada de pontos de interesse (método de caderneta de campo) e marcação de pontos por meio de aparelhos de GPS. A atividade de gabinete deteve-se no levantamento do material cartográfico de apoio, como: as bases cartográficas temáticas da Secretaria de Estado, Planejamento e Coordenação Geral de Mato Grosso -SEPLAN/MT - 2007; imagens dos satélites SPOT TM5 (SEMA/MT) e LANDSAT 5/7 (INPE) e MDE - Modelo Digital de Elevação da Terra (Projeto TOPODATA/INPE). Os materiais formaram um banco de dados temáticos que foi sendo estruturado no recorte e ajuste escalar das bases cartográficas, mosaicamento das imagens de satélite e ajustes radiométricos e espacial, e processamento dos dados raster do MDE, por meio de ferramentas do software ArcGIS 10.3 para extração dos dados altimétricos e clinográficos.

A elaboração do mapa geomorfológico da bacia hidrográfica do rio Tenente Amaral, levou em consideração a constituição das unidades morfoesculturais presentes em sua área, isto é, a unidade do Planalto dos Guimarães e a Depressão Interplanáltica de Rondonópolis (ROSS, 1992; CAMARGO, 2011) e, a partir da análise das características estruturais/esculturais por meio da interpretação das imagens mencionadas foi individualizada 
cada uma das unidades, estabelecendo dois arquivos shapefiles na interface do software de geoprocessamento ArcGIS 10.3.

A partir do reconhecimento das duas unidades morfoesculturais na área da bacia hidrográfica foi feito a análise mais acurada dos fatos geomorfológicos, agora não somente levando em consideração as informações presentes nas imagens de satélite, mas também as que estavam presentes nos mapas hipsométrico e clinográfico. Nesta fase de todo o procedimento foi reconhecida as formas menores de cada uma das duas unidades. Assim, para a unidade morfoescultural da Depressão Interplanáltica de Rondonópolis foram representadas as superfícies erodidas ou de rebaixamento, as formas residuais - morros testemunhos, as rampas de colúvio, as escarpas erosivas e o vale do rio Tenente Amaral, e na unidade do Planalto dos Guimarães foram representadas as voçorocas, as superfícies aplainadas com erosão superficial em meio a áreas de lavouras e de vegetação nativa primária/secundária e as facetas trapezoidais, reveladoras da influência das falhas e/ou fraturas geológicas na evolução do relevo do Planalto na região.

\section{RESULTADOS E DISCUSSÃO}

O contexto dos processos geomorfológicos no sistema São Lourenço e, por sua vez, os da bacia hidrográfica do rio Tenente Amaral, passa pela compreensão da morfodinâmica regional que está sob a custódia do nível de base representado pela vasta superfície alagadiça da Planície do Pantanal (Fig. 2). A circulação de água e sedimentos das superfícies do entorno da planície do Pantanal, como o caso do Planalto e Chapada dos Guimarães, evidencia a condição de "nivelamento" das superfícies a partir dos níveis que definem o setor norte da planície do Pantanal.

A bacia hidrográfica do rio Tenente Amaral apresenta algumas especificidades em relação ao contexto dos demais tributários do setor de médio e alto curso da bacia hidrográfica do rio São Lourenço. Com uma configuração triangular e uma amplitude em torno de 622 metros distribuídos ao longo 50Km da nascente até a jusante, este sub-sistema de drenagem desempenha o papel exclusivo de retirar e transportar material componente das suas superfícies, pois ao longo do rio Tenente Amaral não há superfícies de agradação e o material erodido/transportado pelo sistema é lançado no rio São Lourenço de forma intensa. Este fato é representado pelos depósitos de sedimentos fluviais na margem oposta à de sua confluência 
com o rio São Lourenço, cerca de $12 \mathrm{Km}$ a montante da represa PCH São Lourenço - antiga Zé Fernando.

Figura 2 - Mapa de localização da bacia hidrográfica do rio Tenente Amaral em relação ao nível de base regional, o Pantanal Setentrional.

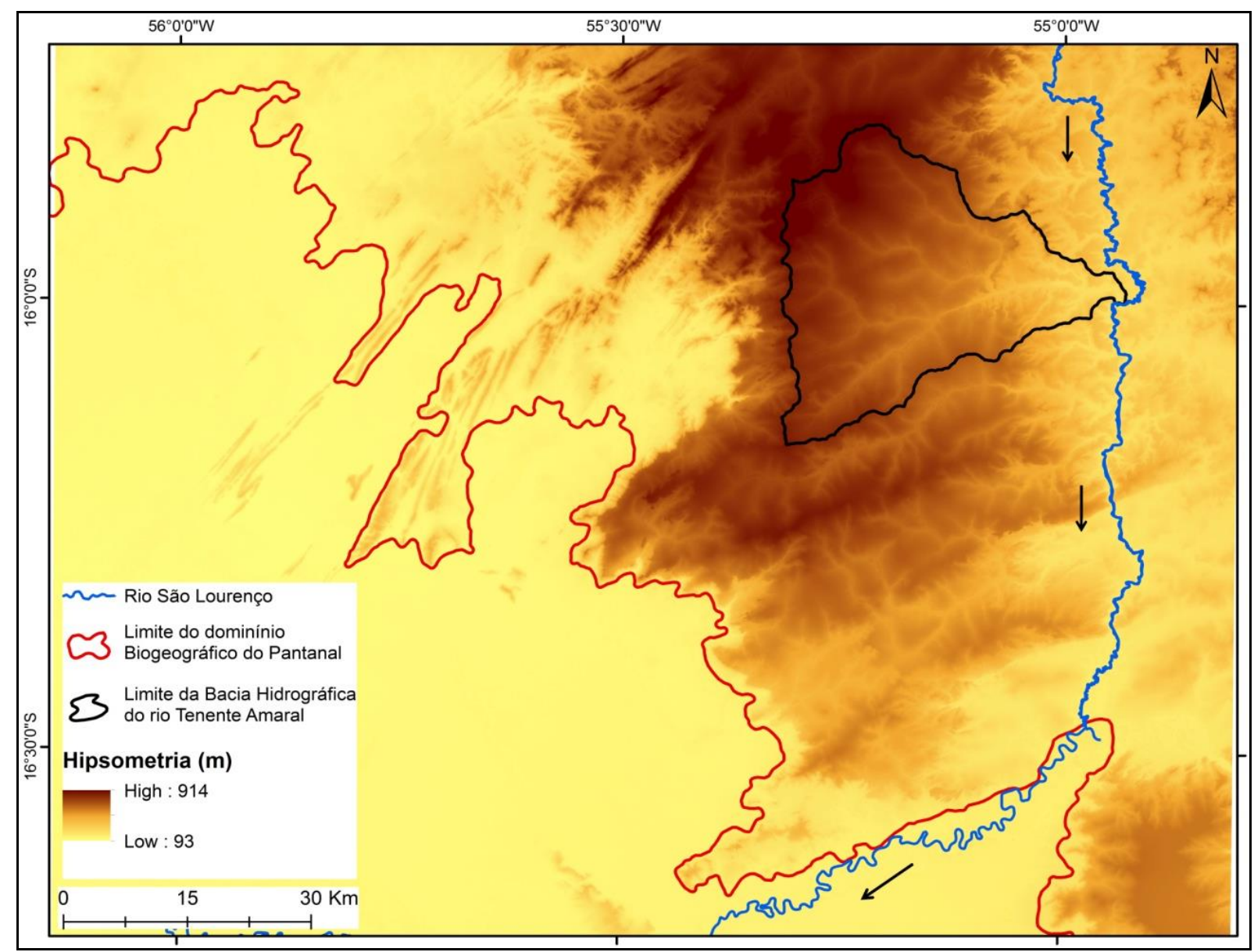

Fonte: Dados cartográficos da Secretaria de Estado de Planejamento e Gestão/MT - SEPLAN (2007) e TOPODATA/SRTM/INPE.

No setor de confluência do rio Tenente Amaral com o rio São Lourenço tem-se o registro de um dos vários resultados vinculados ao uso dos cursos d'água para a geração de energia hidráulico-elétrica. Em 2009 com o término da construção da barragem São Lourenço - antiga Zé Fernando - a intervenção no desempenho sobre a dinâmica de deslocamento dos sedimentos é tanta que em um curto período, cerca de 6 anos, ocorreu à mudança do curso do rio São Lourenço no local de confluência com o rio Tenente Amaral, além da colmatação do setor "abandonado" do rio São Lourenço, conforme está registrando a sequência de cenas das imagens de satélite apresentadas na figura 3. 
Figura 3: Aspectos da dinâmica sedimentar na confluência do rio Tenente Amaral com o rio São Lourenço após implantação da Represa PCH São Lourenço, em Jaciara/Juscimeira MT.

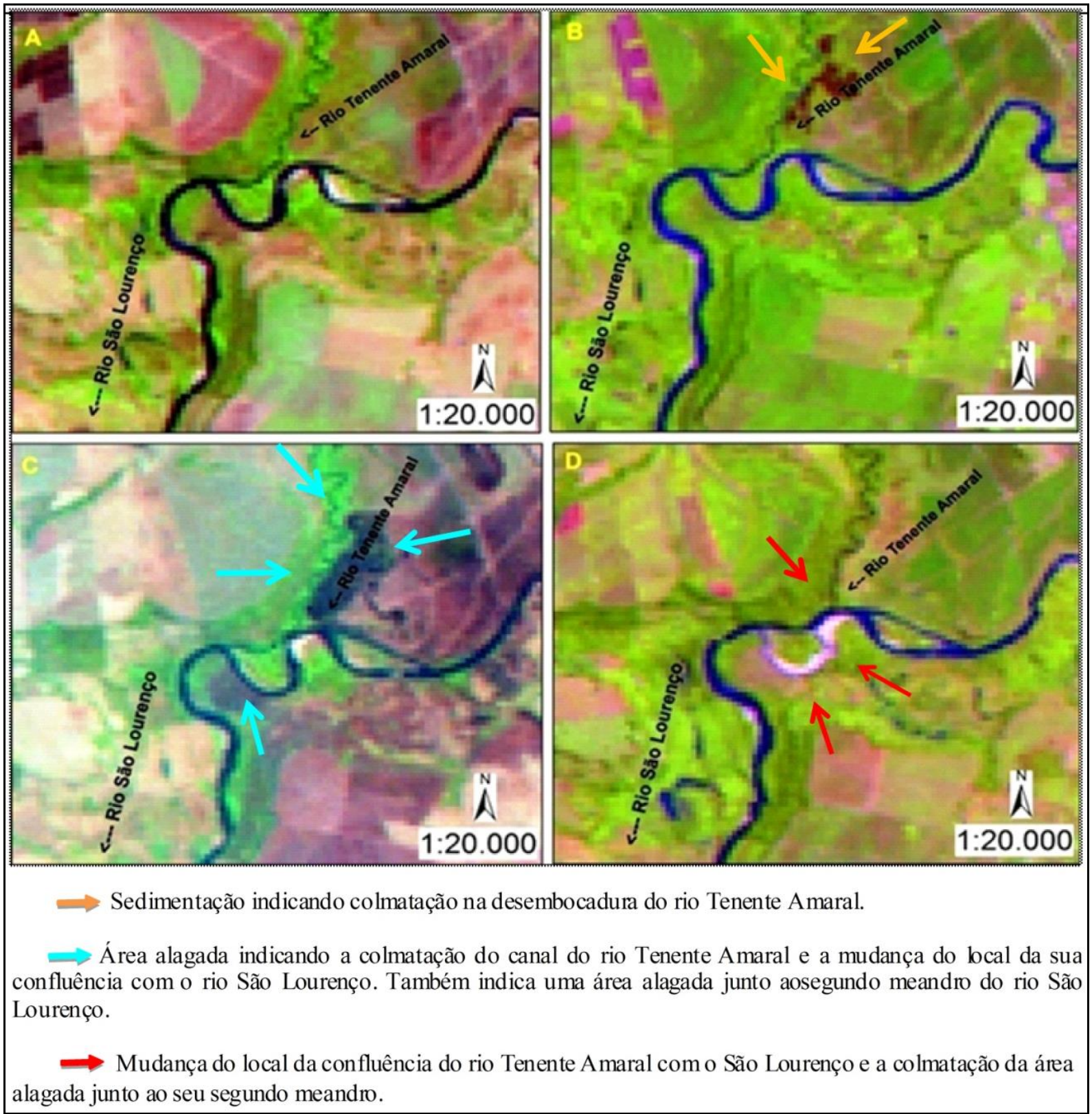

Fonte: INPE - Imagens do LANDSAT 5 - Órbita 226/071 bandas: 543 períodos: 19/08/2008 - 10/01/2009 26/09/2010 - 22/04/2011. Legenda: As cenas são entre os anos: A) 2008; B) 2009; c) 2010, e D) 2011.

A sucessão das informações presentes nas imagens $\mathbf{A}, \mathbf{B}, \mathbf{C}$ e $\mathbf{D}$, mostra a dinâmica fluvial no âmbito da confluência dos dois rios. Na imagem A nota-se a posição de encontro do rio Tenente Amaral diretamente sobre a primeira curva do segundo meandro do rio São Lourenço. Na imagem B a situação continua, porém surge uma área de sedimentação junto a margem esquerda do rio Tenente Amaral. Na imagem $\mathbf{C}$ é possível identificar uma área alagada no lugar do curso principal do rio Tenente Amaral, além da mudança do local da sua desembocadura para a curvatura do primeiro meandro do rio São Lourenço. A imagem D 
expressa a condição de alteração da desembocadura do rio Tenente Amaral com o São Lourenço, mostrando o impacto pós-obra da represa sobre a dinâmica de circulação dos dois rios, pois ambos tem alterações significativas nesta parte dos seus cursos como, por exemplo, a colmatação de meandro e de uma área alagada do rio São Lourenço.

\section{O relevo da bacia hidrográfica do rio Tenente Amaral - MT}

A escolha da área da bacia hidrográfica do rio Tenente Amaral levou em consideração a sua posição geográfica em relação ao contexto geomorfológico regional no que se refere às superfícies do Planalto dos Guimarães e da Depressão Interplanáltica de Rondonópolis. Essa abordagem possibilitou efetivar uma análise simultânea das formas de relevo entre estes dois compartimentos.

Na área em questão, a escala de 1:80.000 adotada na pesquisa possibilitou estabelecer a análise e representação dos principais fatos geomorfológicos que regem sobre as suas superfícies, além da contextualização destas informações em relação aos processos contemporâneos que, em grande parte, explicam a ocorrência dos principais grupos de solos nas superfícies do Planalto e da Depressão Interplanáltica de Rondonópolis, e as informações apresentada na tabela 1 expressam quali-quantitativamente este contexto. 
Tabela 1: Síntese sobre alguns dos indicadores importantes para análise da morfodinâmica na bacia hidrográfica do rio Tenente Amaral/MT.

\begin{tabular}{|c|c|c|c|c|}
\hline \multirow{2}{*}{$\begin{array}{c}\text { Morfoestrutura } \\
\text { / } \\
\text { Morfoescultura }\end{array}$} & \multicolumn{4}{|c|}{ Aspectos do contexto morfodinâmico } \\
\hline & $\begin{array}{c}\text { Padrão de } \\
\text { formas de } \\
\text { relevo } \\
\end{array}$ & Hipsometria(m) & $\begin{array}{c}\text { Declividade } \\
(\%)\end{array}$ & Observações \\
\hline \multirow{5}{*}{$\begin{array}{l}\text { - Borda norte da } \\
\text { Bacia Sedimentar } \\
\text { do Paraná. } \\
\text { - Depressão } \\
\text { Interplanáltica de } \\
\text { Rondonópolis. }\end{array}$} & Escarpas. & $300-450$ & $\begin{array}{c}20-28 \\
>28\end{array}$ & $\begin{array}{l}\text { - Área total: } 12,79 \mathrm{~km}^{2} . \\
\text { - Afloramento de rocha (Litossolos). }\end{array}$ \\
\hline & $\begin{array}{l}\text { Rampas } \\
\text { coluvionares. }\end{array}$ & $233-300$ & $\begin{array}{c}7-13 \\
13-20\end{array}$ & $\begin{array}{l}\text {-Área total: } 68,47 \mathrm{~km}^{2} . \\
\text { - Arenização (Neossolos } \\
\text { Quartzarênicos), Argilização } \\
\text { (argissolos) e Alitização. }\end{array}$ \\
\hline & $\begin{array}{lr}\text { Formas } & \text { residuais } \\
- & \text { Morros } \\
\text { testemunho. }\end{array}$ & $\begin{array}{l}300-450 \\
450-600\end{array}$ & $\begin{array}{l}7-13 \\
13-20 \\
20-28\end{array}$ & $\begin{array}{l}\text { - Área total: } 0,27 \mathrm{~km}^{2} . \\
\text { - Arenização (Neossolos } \\
\text { Quartzarênicos, Litossolos ). }\end{array}$ \\
\hline & $\begin{array}{l}\text { Superfície } \\
\text { erodida ou de } \\
\text { rebaixamento. }\end{array}$ & $259-430$ & $\begin{array}{c}<3 \\
3-7 \\
7-13\end{array}$ & $\begin{array}{l}\text { - Área total: } 71,39 \mathrm{~km}^{2} . \\
\text { - Formas dissecadas convexas. } \\
\text { - Argilização (Argissolos). }\end{array}$ \\
\hline & Voçorocamentos & $\begin{array}{l}300-450 \\
450-600\end{array}$ & $\begin{array}{l}<3 \\
3-7 \\
7-13\end{array}$ & $\begin{array}{l}\text { - Ârea total: } 0,80 \mathrm{~km}^{2} \text {. } \\
\text { - No de ocorrência: } 39 \text {. } \\
\text { As ocorrências de voçorocamentos } \\
\text { estão presentes nas superfícies acima } \\
\text { dos } 730 \text { metros. } \\
\text { - Erosão concentrada (transporte de } \\
\text { material sedimentar arenoso). }\end{array}$ \\
\hline \multirow[t]{3}{*}{$\begin{array}{l}\text { - Borda norte da } \\
\text { Bacia Sedimentar } \\
\text { do Paraná. }\end{array}$} & $\begin{array}{l}\text { Facetas } \\
\text { Trapezoidais }\end{array}$ & $450-750$ & $<3-5$ & $\begin{array}{l}\text {-Falhas como fator de explicação de } \\
\text { evolução de formas de relevo na área } \\
\text { da bacia na unidade morfoescultural } \\
\text { do Planalto dos Guimarães. }\end{array}$ \\
\hline & $\begin{array}{l}\text { Formas } \\
\text { dissecadas com } \\
\text { topos convexos } \\
\text { junto aos vales } \\
\text { dos rios de maior } \\
\text { ordem. }\end{array}$ & $\begin{array}{l}300-450 \\
450-600 \\
>750\end{array}$ & $\begin{array}{l}3-7 \\
7-13\end{array}$ & $\begin{array}{l}\text { - Área total: } 101,26 \mathrm{~km}^{2} . \\
\text { Algumas superfícies apresentam } 13 \\
\text { a } 20 \% \text { de declividade. Arenização } \\
\text { (Neossolos Quartzarênicos) e } \\
\text { Alitização. } \\
\text { - Erosão superficial em áreas de } \\
\text { vegetação nativa primária e/ou } \\
\text { secundária. }\end{array}$ \\
\hline & $\begin{array}{l}\text { Formas } \\
\text { dissecadas com } \\
\text { topos convexos e } \\
\text { tabulares. }\end{array}$ & $\begin{array}{l}300-450 \\
450-600 \\
>750\end{array}$ & $\begin{array}{c}<3 \\
3-7\end{array}$ & $\begin{array}{l}\text { - Área total: } 614,23 \mathrm{~km}^{2} . \\
\text { - Pequenas áreas com superfícies } \\
\text { entre } 7 \text { e } 13 \% \text { de declividade - } \\
\text { Verticalização da drenagem. } \\
\text { - Latolização (Latossolos), } \\
\text { Argilização, (Argissolos) } \\
\text { - Erosão superficial em áreas de uso } \\
\text { agropecuário. }\end{array}$ \\
\hline
\end{tabular}

Fonte: Adaptado de JESUZ (2014).

Assim, a morfologia da bacia hidrográfica do rio Tenente Amaral, conforme representado no mapa da figura 4 mostra as particularidades da morfodinâmica em relação ao conjunto de formas associadas às superfícies do Planalto dos Guimarães e da Depressão Interplanáltica de Rondonópolis. 
Figura 4: Mapa morfológico da bacia hidrográfica do rio Tenente Amaral - MT.

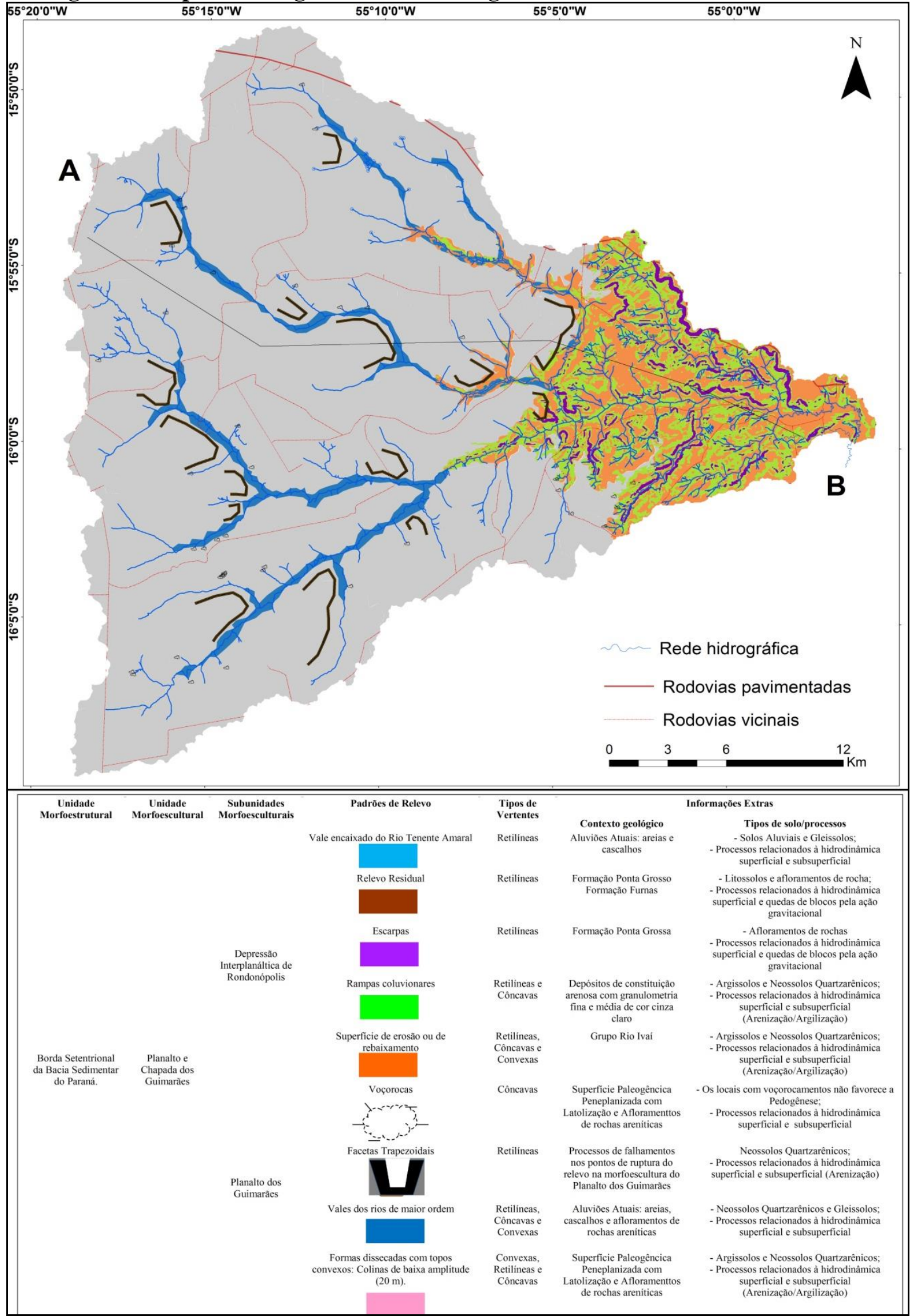

Fonte: Dados de campo 2013/2014/2015 
A análise permitiu verificar que nas superfícies do Planalto o contexto morfodinâmico representa a sua relativa condição de "estabilidade", onde vigoram os processos relacionados à morfopedogêneses e tendo como resposta os espessos perfis de Latossolos e a formação das coberturas lateríticas. E, à medida que as superfícies vão sendo erodidas, em especial ao longo dos eixos dos rios de maior ordem, tem-se uma maior dinâmica em relação aos processos vigentes que respondem pela ocorrência dos Neossolos Quartzarênicos em consonância com processos de arenização, além da argilização, alitização, conforme a condição da superfície topográfica. Estas inferências tiveram base na ideia da estreita relação entre os processos que rege a morfogênese com os da pedogênese.

A morfogênese, como bem destaca Espindola (2010), revela as fases de evolução do relevo a partir dos graus de desenvolvimento dos solos em consonância com as causas tectônicas e mudanças climáticas. As datações relativas em conjunto com a análise sedimentológica do material das superfícies, associado aos critérios altimétricos das formas testemunhas de antigos processos, revela a instituição de uma morfopedogênese, ou uma pedomorfogênese, uma vez que ambos são dependentes dos mesmos fatores de formação.

Sendo assim, na área da bacia hidrográfica em questão a parcela das superfícies do planalto está vinculada diretamente aos elementos da paisagem relacionados aos níveis topográficos de 800 a 500 metros, onde prevalece uma morfologia de colinas com topos planos e de suave convexidade que, de acordo com Cabral e Cabral (2010), apresentam a seguinte classificação em termos de dimensões interfluviais: (I) pequeno: < 2000m; (II) médio: de 2000 a 5000m; (III) grande: de 5000 a $8000 \mathrm{~m}$ e muito grande: $>8000 \mathrm{~m}$. Seccionados por um número pouco expressivo de rios, os interflúvios muito planos e "nivelados" de grandes dimensões interfluviais revelam uma condição da evolução das formas topográficas sujeitas aos processos de decomposição das estruturas litológicas, fato comprovado pela ocorrência de vastas áreas recobertas por espessos mantos de material pedogeninizado/neoformados em superfície.

Por outro lado, nas superfícies deste setor da bacia hidrográfica do rio Tenente Amaral ocorre vários eventos de voçorocamentos localizados junto às nascentes dos cursos d'água situados entre os níveis topográficos de 300 a 600 metros de altitude. Esse é um fato interessante, pois expressa outros eventos da morfodinâmica regional que explicam o arrasamento da superfície do Planalto e ampliação da Depressão Interplanáltica de Rondonópolis, vinculados a mudanças no nível de base local/regional. 
É importante ressaltar que nos continentes as superfícies sempre estão sujeitas as variações do nível de base global, entretanto fatos de uma morfodinâmica local/regional "esporádica ou não" deve ser considerado nas análises efetivadas sobre a evolução do relevo em diferentes escalas de espaço e tempo. Na escala adotada no trabalho foi possível perceber evidências de sucessivos patamares de vertentes e/ou estruturais, localizados a partir do médio para o alto setor da área em questão onde vigoram, conforme as informações contidas no mapa da figura 4, eventos de erosão superficial em meio a lavouras e em meio à vegetação nativa primária e/ou secundária.

Na Depressão Interplanáltica de Rondonópolis os níveis topográficos das superfícies estão situados entre as cotas de 233 a 450 metros. Na área da bacia hidrográfica do rio Tenente Amaral está unidade contempla o conjunto de formas rebaixadas em relação às superfícies do Planalto e Chapada dos Guimarães, expressando características intrínsecas às unidades geomorfológicas dissecadas no estado de Mato Grosso, conforme destacadas por Ross (1992) e Camargo (2011).

Particularmente a unidade do Planalto dos Guimarães perfaz o setor da bacia hidrográfica estudada onde ocorrem as formas dissecadas de baixa amplitude (20m) - Relevo de colinas suaves e tabulares, os vales dos rios de maior ordem, e os eventos de voçorocamentos. A Depressão Interplanáltica de Rondonópolis é a mais diversificada em termos de formas topográficas. Nela encontra-se o vale principal do rio Tenente Amaral, relevo residual, escarpas de erosão, rampas coluvionares e superfície de erosão ou de rebaixamento, conforme representado no perfil topográfico da figura 5.

Figura 5: Perfil topográfico das unidades morfológica na área da bacia hidrográfica do rio Tenente Amaral - MT. Segmento AB no mapa da figura 4.

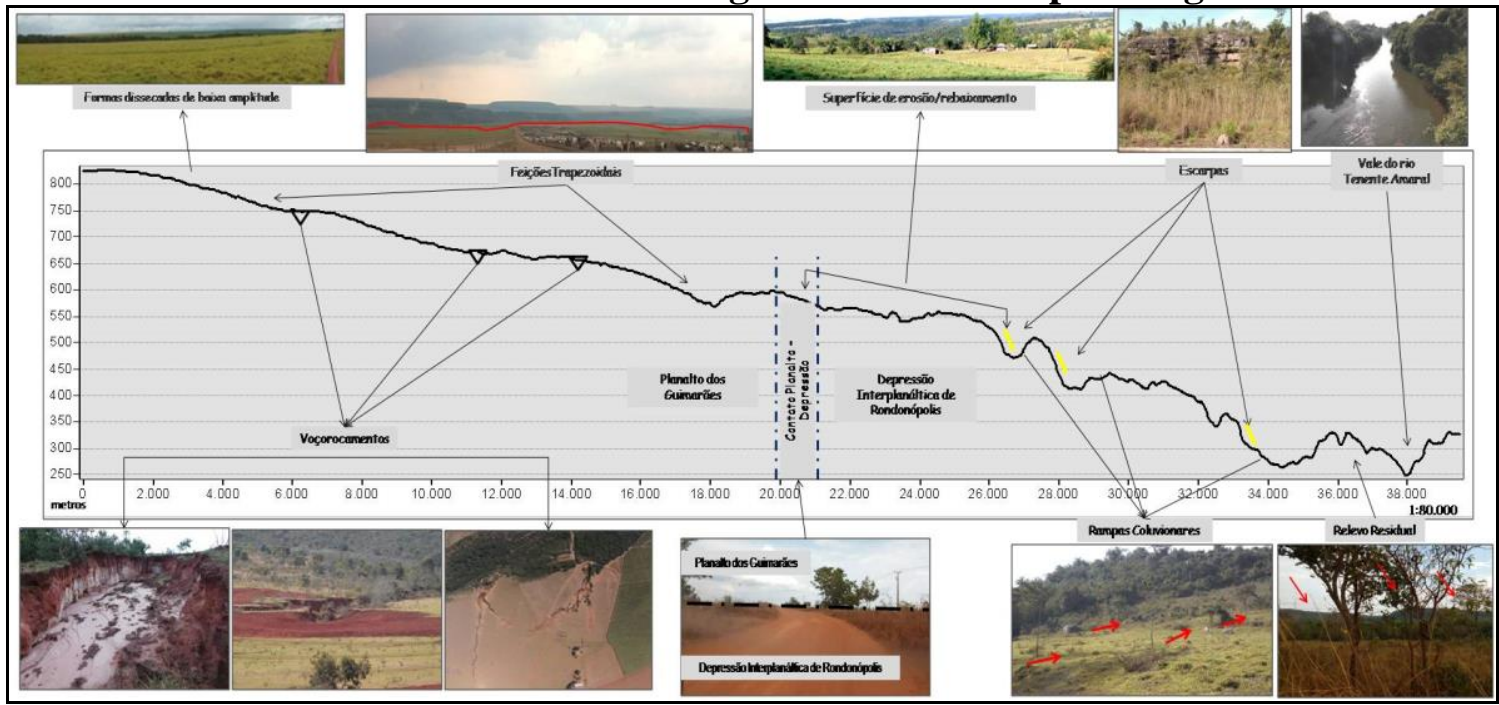

Fonte: Levantamento de campo 2013/2014/2015. 
Assim, o relevo que corresponde à unidade morfológica do Planalto representado pelas superfícies em forma de colinas côncavas e tabulares resulta de uma ação geoquímica da água em meio às estruturas sedimentares associados a uma latolização de longo prazo, enquanto os vales dos rios de maior ordem e os eventos de voçorocamentos têm a sua origem e evolução vinculada a eventos hidromórficos e mecânicos associados ao sistema de drenagem sob contexto de escala de ação local/regional, além da ação Neotectônica (PRADO et al., 2014).

Os processos que respondem pelo conjunto de formas do relevo as quais permite estabelecer a unidade morfológica da Depressão Interplanáltica de Rondonópolis, exceto o vale principal do rio Tenente Amaral, são adversos aqueles que explicam a gênese das superfícies do Planalto como um todo. Assim, o conjunto de formas subdivididas em relevo residual, escarpas de erosão, rampas coluvionares e superfície de erosão ou de rebaixamento resultam do amplo processo do ciclo mais recente de nivelamento das superfícies do Planalto dos Guimarães. As particularidades em relação aos processos que deram origem ao relevo residual e das escarpas tem relação com ação mecânica por parte dos rios e, posteriormente a queda de blocos devido à ação da gravidade. As rampas coluvionares surgem a partir da acumulação do material rochoso nos sopés das escarpas e dos morros que compõem o relevo residual. A morfodinâmica nestas formas remete-se a processos de arenização, argilização e alitização, conforme as condições das superfícies e a idade do material coluvionado.

A superfície de erosão ou de rebaixamento é representada por topografias mais dissecadas e de maior amplitude em relação ao relevo do Planalto. Nesta área, o contexto morfopedológico principal está sob a custódia dos processos de argilização, arenização,alitização e gleização, este situado ao longo dos vales dos rios de maior ordem, expressando uma das conjunturas das unidades de paisagem advinda dos efeitos vinculados ao rebaixamento das superfícies do Planalto na sua condição de borda de bacia de sedimentação, sob efeitos de um ambiente climático com temperaturas elevadas e duas estações estremas em termos de precipitação.

Por outro lado, a partir destas análises também é importante destacar as singularidades de cada uma das subunidades elencadas, pois no meio acadêmico/científico são inúmeras as dificuldades em relação à construção do conhecimento sobre as diferentes unidades de paisagem desta e de outras áreas do estado de Mato Grosso. É comum ouvir a expressão "as superfícies dos Planaltos são homogenias e estáveis", referindo-se ao contexto das formas topográficas e dos produtos presentes sobre as mesmas. 
Sendo assim, o detalhamento em relação a cada uma das particularidades representadas no mapa da figura 4 teve a preocupação de indicar elementos para apoiar os trabalhos desenvolvidos pelos diferentes profissionais na sua prática de pesquisa e ensino.

Assim, referente às formas dissecadas de baixa amplitude (20m) o observador ao contemplar in loco as formas de colinas tabulares terá uma vista distante no horizonte com uma sensação de estar em uma grande planície, visualizando pouco o sistema de drenagem. No detalhe estas formas correspondem aos interflúvios de grande dimensão recobertos por material de coloração vermelho/amarelo e amarelo que revelam a relativa condição de drenagem destes meios. As colinas suaves estão consorciadas às morfologias tabulares e uma das formas de percebê-las é observar as cores do material superficial presente nelas, grande parte vermelho, além da melhor visualização do sistema de drenagem. Nas cartas topográficas as formas tabulares apresentam pouca variação em relação às cotas altimétricas e a densidade de rios é muito baixa. As colinas suaves nas cartas topográficas também apresentam baixa variação em relação às cotas altimétricas, porém, no contexto local/regional, a densidade de rios é um pouco mais significativa.

$\mathrm{Na}$ superfície planáltica da área em questão outro fato perceptível nas cartas topográficas é a ocorrência de facetas trapezoidais, expressando a influência das fraturas e falhas geológicas no desenvolvimento das formas do relevo não só da bacia hidrográfica do rio Tenente Amaral, mas de várias outras como, por exemplo, a bacia hidrográfica do Córrego Ibó e Fortaleza.

Em relação aos vales dos rios de maior ordem, in loco, o observador terá como elemento chave para a sua identificação o nível do terreno, a presença ou não de água e, vegetação típica, além da cor cinza escuro e cinza clara do material superficial presente nestas áreas. Nas cartas topográficas estas superfícies apresentam níveis mais baixos, expressando configurações que lembram uma sucessão de letras "V" e às vezes "U"e, nas imagens de satélite são identificados pelos tons mais escuros com ou sem vegetação típica dos vales ao longo dos rios.

Na superfície planáltica da bacia hidrográfica do rio Tenente Amaral a identificação das voçorocas, tanto in loco quanto nas imagens de satélite apresenta particularidades que facilitam o seu reconhecimento. A partir do entendimento e da distinção ente ravina e voçoroca, de certo modo é fácil identificá-las no campo e nas imagens de satélite, principalmente adotando escala grande de resolução. In loco o observador visualizará um "rasgo" na superfície com ou sem vegetação em seu interior e, de acordo com a estação do 
ano, também é possível verificar a presença de água na parte de maior entalhe. Elas estão situadas, preferencialmente, junto às cabeceiras dos rios de menor ordem, ocupando a posição que vai do meio para a base da vertente, fato que pode ser observado pelo aumento da declividade nestas superfícies. Em cartas topográficas e/ou nos modelos plano altimétrico em escalas de maior detalhe, as voçorocas tem relação com a configuração das curvas de nível em "V", sem muita variação da amplitude topográfica (JESUZ e CABRAL, 2016).

Nas imagens de satélite a sua identificação está condicionada a escala da imagem adotada. No contexto geral, o relevo de voçorocas apresenta uma diversidade em relação à cobertura vegetal, dimensão e profundidade do entalhamento, e os tipos de estruturas da qual deriva. Tais aspectos devem ser considerados na escolha dos produtos provenientes dos sensores remotos para fins de estudo destas formas e seus respectivos processos. No caso da bacia hidrográfica do rio Tenente Amaral, na imagem destacada na metodologia do trabalho elas aparecem em pequenas parcelas com maior diversidade em relação à variação das cores, indo de tons rosa a verde, ambos variando do claro ao escuro, conforme a condição da cobertura vegetal, da umidade e do tipo de material da qual deriva.

O compartimento geomorfológico da Depressão Interplanáltica de Rondonópolis contempla uma maior diversidade em seu contexto morfológico onde a sensação de "monotonia" em termos topográfico, sentida ao percorrer as superfícies do Planalto, deixa de se manifestar. Nesta área o conjunto das formas do relevo sugere uma maior dinâmica e/ou diversidade em relação aos processos de sua formação, resultando em particularidades de formas que, especificadamente, correspondem à superfície erodida ou de rebaixamento, as rampas coluvionares, as formas residuais - morros testemunho e o vale principal do rio Tenente Amaral.

Em relação ao contexto geral do relevo da superfície da Depressão Interplanáltica de Rondonópolis, na área em questão, apresenta várias especificidades que se destacam tanto nas cartas topográficas, quanto nas imagens de satélite e no campo. Deste modo, a sua identificação in loco chama a atenção pela presença de colinas com topos convexos de maior amplitude em relação às superfícies do Planalto propriamente dito.

Nas fontes de informação já mencionadas os elementos indicadores das particularidades da superfície de rebaixamento mostram que nas cartas topográficas essa parcela da Depressão Interplanáltica de Rondonópolis vai apresentar, predominantemente, níveis inferiores em relação aos que representam as superfícies do Planalto, além da equidistância das curvas de nível ser mais próximas, demonstrando superfícies mais 
dissecadas do que as que ocorrem no Planalto. Nas imagens de satélite esse fato se apresenta pela predominância da cor verde e sua variação. As demais cores ocorrem em menor frequência, abrangendo menores áreas.

As escarpas são fácies de reconhecer no campo e nas cartas topográficas. No campo elas chamam a atenção pela arquitetura dos paredões, e nas cartas topográficas devido à presença de curvas de nível muito próximas umas das outras, distribuídas conforme o contexto do relevo escarpado presente, ou seja, paredões de vales encaixados ou nas bordas do relevo residual. Na imagem de satélite as escarpas estão registradas com cores escuras, principalmente o verde.

A unidade de relevo correspondendo às rampas coluvionares pode ser identificada a partir das escarpas e do relevo residual, pois constituem formas derivadas do material tombado pela ação da gravidade que se depositam na base das referidas superfícies. Embora sendo fácil reconhecer o relevo residual na bacia hidrográfica em questão, a identificação do mesmo também pode ser sustentada pelo o que está sendo colocado sobre o reconhecimento das escarpas e das rampas coluvionares.

Enfim, em relação ao vale principal do rio Tenente Amaral o reconhecimento nas cartas topográficas também perpassa pelas informações referentes à distribuição e os valores das curvas de nível com ligação direta às topografias das rampas coluvionares e das escarpas.Em campo constitui as superfícies onde é possível verificar material de ambiente topográfico em condições de intensa hidromorfia, além de inúmeros afloramentos de rochas. A sua condição de rio de borda de bacia sedimentar apresenta um aspecto muito visado para o lazer no Estado, ou seja, o leito escalonado dando origem a várias cachoeiras e corredeiras, fator que explica a localização de vários balneários junto a este rio no município de Jaciara/MT.

\section{CONSIDERAÇÕES FINAIS}

A bacia hidrográfica do rio Tenente Amaral, apresenta um contexto geomorfológico que expressa às particularidades vinculadas ao relevo derivados de estruturas sedimentares, especificadamente o setor da borda norte da Bacia Sedimentar do Paraná, sob o empenho do sistema de drenagem do rio São Lourenço.

O procedimento adotado permitiu cumprir com o objetivo proposto inicialmente, pois possibilitou o reconhecimento e o mapeamento do relevo da bacia hidrográfica do rio Tenente Amaral na escala 1:80.000. A metodologia adotada viabilizou a análise dos fatores que 
respondem pela evolução do relevo na área em questão, além de ter possibilitado destacar algumas informações sobre o reconhecimento das formas do relevo identificadas e mapeadas a partir de três fontes de informação, isto é, as cartas topográficas, imagem de satélite e levantamento de campo.

A pesquisa revelou que a área do sistema hidrográfico em questão faz parte do contexto geomorfológico regional responsável pelo rebaixamento do Planalto dos Guimarães e ampliação da Depressão Interplanáltica de Rondonópolis. Estes dois conjuntos de formas resultam de ações morfodinâmicas diferenciadas, fato evidenciado pela própria conjuntura das variedades predominantes dos solos e suas respectivas características. O contexto dos aspectos vinculados às condições das variedades dos solos presentes em cada uma das unidades morfológicas da bacia hidrográfica deve ser compreendido numa conjuntura da apropriação da natureza, pois as evidências de caráter ambiental se manifesta de forma diferente em cada uma destas unidades de relevo, demandando conhecimentos específicos e em escala de maior detalhe.

Por outro lado, o trabalho evidencia a importância das pesquisas sobre o desenvolvimento do relevo nas superfícies planálticas em Mato Grosso, pois estas superfícies são extremamente visadas pelo setor de produção primária no Estado e região. O conhecimento destas áreas obtidos a partir da perspectiva da Geomorfologia possibilita, de antemão, o reconhecimento dos solos e seus respectivos indicadores de fragilidade. É importante destacar que a área em questão faz parte de um dos vários sistemas de drenagem que se dirigem para o setor norte da planície do Pantanal, tornando importante o conhecimento da sua morfodinâmica, sob contexto das especificidades envolvendo a apropriação desta e de outras áreas do entorno da referida planície. O conhecimento do relevo para a ação do comitê de bacias hidrográficas também se faz necessário no reconhecimento do sistema de drenagem como um todo, e a determinação das áreas de nascentes dos cursos d’água, principalmente nas superfícies do Planalto dos Guimarães.

Constatou-se que o sistema de drenagem do rio Tenente Amaral desempenha o papel de rebaixamento do Planalto dos Guimarães, arrancando e transportando material do Planalto e da Depressão Interplanaltica de Rondonópolis para a planície do Pantanal e além desta, pois todos os conjuntos de formas constatados nas duas unidades mapeadas são formas de erosão. 


\section{REFERÊNCIAS}

AB'SÁBER, A. N. Participação das depressões periféricas e superfícies aplainadas na compartimentação do Planalto Brasileiro. Geomorfologia, São Paulo, n. 28, p. 1-38, 1972.

BERTRAND, G. Paisagem e Geografia física global: esboço metodológico. Cadernos de Ciências da Terra, São Paulo: IGEOG/USP, n. 13, 27p. (Tradução de Olga Cruz). 1971.

BRASIL. DEPARTAMENTO NACIONAL DA PRODUÇÃO MINERAL. PROJETO RADAMBRASIL. Folha SE. 21. Corumbá. Rio de Janeiro, 1982.

CABRAL, T. L.; CABRAL, I. L. L. Abordagem morfopedológica como subsídio ao estudo da distribuição geográfica dos Latossolos no município de Sorriso-MT. In: Anais XVI Encontro Nacional dos Geógrafos. Porto Alegre-RS, 2010.

CAMARGO, L (Org.). Atlas de Mato Grosso: abordagem socioeconômico-ecológica. Cuiabá - MT: Entrelinhas, 2011.

CASSETI, V. Ambiente e apropriação do relevo. São Paulo: Contexto, 1991.

CASSETI, V. Geomorfologia. [S.1.]: [2005]. Disponível: http://www.funape.org.br/geomorfologia/. Acesso em 2018.

CASTRO, S. S de; SALOMÃO, F. X. de T. Compartimentação morfológica e sua aplicação: Considerações Metodológicas. Revista GEOUSP. № 7. 2000.

CHOLLEY, A. Morphologie structural et morphologieclimatique. Annales de Géographie, no 137 , pp. 321-335, 1950.

ESPINDOLA, C. R. A Pedologia e a evolução das paisagens. Revista do Instituto Geológico, São Paulo, 31 (1/2), 67-92, 2010.

GERASSIMOV, I. P.; MECERJAKOV, J.A. Morphoestructure. In: FAIRBRIDGE, R. W. (ed). The Encyclopedia of Geomorfoly. Reinhold Book, NY, 1968.

JESUZ, C. R.; CABRAL, I. L. L. A morfodinâmica da Bacia Hidrográfica do Rio Tenente Amaral - MT. Ra'e Ga, Curitiba, v. 38, p321-344, Dez/2016.

LATRUBESSE, E. M., RODRIGUES, S. C., MAMEDE, L. Sistema de classificação e mapeamento geomorfologicos: Uma nova proposta. Geosul. vol. 14 (17), 682-687. 1998.

MONTEIRO, C. A. F. Geossistemas: a história de uma procura. São Paulo: Contexto, 2000.

PENCK, W. Morphological Analysis of land form.Macmillanand CO, London. 1953.

PRADO, R.J; CABRAL, I. de L. L; SILVA, A. P. M; SOLORZANO, P. E. M; ALBUQUERQUE, A. P. A. Caracterização de material laterítico do Planalto e Chapada dos Guimarães/ MT por EDX, XRD e Espectroscopia Mössbauer. Revista Brasileira de Geomorfologia, v. 15, p. 619-637, 2014.

ROSS, J. L. S. Análise e síntese na abordagem geográfica da pesquisa para o planejamento ambiental. Geografia, Rio Claro, vol. 9, pp.65-75, 1995. 
ROSS, J. L. S. Brazilian Relief: strutures and Forms. Revista do Departamento de Geografia (USP), v. 25, p. 42-58, 2013

ROSS, J. L. S. Ecogeografia no Planejamento Ambiental Territorial. Sociedade e Território (Natal), v. 20, p. 7-39, 2008.

ROSS, J. L. S. O registro cartográfico dos fatos Geomorfológicos e a questão da taxonomia do relevo. Revista do Dep. de Geografia. $n^{\circ}$ 6. (17- 29) FFLCH/USP. São PauloSP. 1992.

ROSS, J. L. S. O Relevo Brasileiro, as Superfícies de aplainamento e os Níveis Morfológicos. Rev. Dep.Geografia (USP) v.5, p. 7-24, 1991.

SEPLAN. Secretaria de Estado de Planejamento e Coordenação Geral. Projeto de Desenvolvimento Agroambiental do Estado de Mato Grosso - PRODEAGRO. Mato Grosso: solos e paisagens. Cuiabá - MT. 2007.

SOTCHAVA, V. B. O estudo de geossistemas. Métodos em questão. São Paulo, n. 16, 1977.

TARIFA, J. R. Mato Grosso: clima: análise e representação cartográfica. (Série recursos naturais e estudos ambientais). Cuiabá, MT: Entrelinhas, 2011.

TRICART, J. Ecodinâmica. Rio de Janeiro: IBGE, 1977.

VASCONCELOS, T. N. N. Interpretação morfopedológica da Bacia do Rio Tenente Amaral - Jaciara/MT: condição básica para sua caracterização ambiental. Cuiabá-MT. Dissertação de Mestrado. Universidade Federal de Mato Grosso, Cuiabá 1998.

WWF-BRASIL. Monitoramento das alterações da cobertura vegetal e uso do Solo na Bacia do Alto Paraguai - Porção Brasileira - Período de Análise: 2008 a 2010. Iniciativa: CI - Conservação Internacional, ECOA - Ecologia e Ação, Fundación AVINA, Instituto SOS Pantanal, WWF- Brasil. Brasília, 2011.

Recebido em Dezembro de 2019

Aceito em Abril de 2020

Publicado em Julho de 2020 